(6) "Étude géologique du Bassin houiller de Liège. Le massif de Herve. Région orientale", by H. Chaudoir, Ch. Ancion, A. Pastiels

These are splendidly produced in the style familiar to those who know Belgian geological publications. Most of them give elaborate details of the sequences they describe. The second one, that by Deleers and Pastiels, provides statistical information on collections of the small shells of the genus Anthraconauta which, as in some southern British coalfields, locally becomes the dominant group in the Belgian Coal Measures. The completion of these studies may show whether these shells can be used in more detailed correlation in the zones below the Phillipsii Zone.

British geologists have noted with much pleasure the successful start made by the new Association and will be keenly interested to see its further contributions to the exploration of the Belgian coalfields. The address of the Association pour l'Etude de la Paléontologie et de la Stratigraphie houillères is 31 Rue Vautier, Brussels, 4.

A. E. Trueman

\section{BIOCHEMISTRY OF FERTILIZATION AND THE GAMETES}

$\mathrm{F}^{\mathrm{o}}$ OR centuries past the scientific mind has been striving to elucidate the many-sided aspects of the process of fertilization. In modern times interest has centred for several decades chiefly around the lower forms of animal life; here fertilization is accomplished externally, thereby facilitating in vitro study of the finer mechanism of the processes set in motion by the fusion of the gametes. The developments in the biochemistry of fertilization and the gametes in mammals lagged at first behind the investigations on lower animals, but much progress has been made recently, not a little of the stimulus having been derived from the steadily increasing practice of artificial insemination in animal breeding. Largely empirical in its pioneer phases, the practice of artificial insemination in many parts of the world, including Great Britain, has led to the accumulation of a wealth of observations on the behaviour and the properties of the sperm cell outside the confines of the male body. The advent and perfection of powerful new aids to biological research, such as, for example, electron and phase-contrast microscopy, opened up new possibilities towards the elaboration of techniques with which to pursue stage by stage the process of fertilization.

To give its members and others interested in these problems something of a synopsis concerning the fundamental aspects and recent research trends in this field, the Biochemical Society held on February 17 a one-day symposium on "The Biochemistry of Fertilization and the Gametes".

The proceedings (which will be published in due course) were opened by Dr. A. S. Parkes (National Institute for Medical Research, Mill Hill), and the first address was given by his colleague, Dr. Audrey U. Smith, who dealt with "Fertilization in vitro of the Mammalian Egg" in the light of recent investigations carried out by herself, and also by Chang, Moricard, Austin and others. Work of this kind requires a rigorously controlled technique for the collection of the unfertilized eggs, since there is always the danger that, even without fertilization, mammalian eggs may readily become activated by certain manipulations and segment parthenogenetically. The successful fertilization in vitro of mammalian eggs requires photographic proof of the attachment of the spermatozoon to the egg surface, of its penetration through the membrane and of the subsequent development and fusion of the male and female pronuclei. Dr. Smith gave a critical appraisal of the older work, none of which satisfied fully these requirements. She indicated, however, that studies in this field are at last approaching a final positive solution.

The next paper, on "Mammalian Semen: Com. position, Metabolism and Survival", was given by Dr. T. Mann (Molteno Institute, Cambridge). Biochemical studies on semen in general, and on spermatozoa in particular, are unique in some respects: in that they concern cells of one type only which are not capable of division or multiplication, and which are endowed by Nature with two unusual properties, fertility and motility, both of which form most valuable and specific criteria for the assessment of sperm activity. As a result of recent studies, it is now clear that the spermatozoa themselves possess only a relatively small intracellular nutrient reserve, and depend for their survival largely on extracellular nutrients such as the seminal plasma, the secretions of the female reproductive tract, or the artificial diluents used for the storage of semen. The seminal plasma is distinguished by a high concentration of fructose, citric acid, choline (free and bound) and a number of enzymes, including several phosphatases. Anaerobically the spermatozoa metabolize fructose to lactic acid; aerobically the fructolysis is followed by secondary oxidative processes. There are distinct metabolic differences between epididymal and ejaculated spermatozoa, and also between spermatozoa of different species.

"Hormonal and Nutritional Factors in the Metabolism of the Male Accessory Organs of Reproduction" were described by Dr. Cecilia Lutwak-Mann (Biochemical Laboratory, Cambridge), who said that, in contrast to the numerous histological studies, there was until recently a scarcity of biochemical data concerning the male accessory organs. A new phase in this field was initiated when it was found that the metabolic activity of the accessory glands is accurately and sensitively expressed in the secretion by these organs of certain specific substances such as fructose and eitric acid. The secretory function of the accessory organs is closely dependent upon the activity of the male sex hormone, which is subordinated to hypophyseal control. The relationship between secretory ability and hormonal function has made it possible to develop the chemical analysis of the individual accessory secretions, and of the seminal plasma as a whole, into a quantitative method for the detection and assessment of various stages of hormonal activity. The new method has been applied to the study of $a$ whole range of problems, including the metabolic properties of transplants from male accessory organs, time relationship between the onset of spermatogenesis and the secretion of fructose in the accessory organs, identification of citric acid as metabolite of the rat female prostate, assessment of the androgenic potency of progesterone, and many others. Malnutrition, through its adverse effects on the gonadotrophic function of the pituitary gland, has been found to reduce the metabolic activity of the male accessory organs to a low level not very different from that prevailing in castrated or hypophysectomized animals. 
The presence in a single semen ejaculate of several hundreds of millions of spermatozoa, when only one is ultimately needed for the fertilization of the ovum, has always puzzled biologists. The suggestion has been put forward that a large number of spermatozoa in the vicinity of the egg may be essential in order to create around the egg a high concentration of hyaluronidase for the dispersal of the egg-cumulus. This concept, which a few years ago enjoyed much popularity, has been subjected to searching criticism in recent years, and the present position regarding sperm hyaluronidase was discussed at the symposium by Dr. G. I. M. Swyer (University College Hospital Medical School, London) in a paper on "Hyaluronidase and Fertilization". Attempts to link the activity of sperm hyaluronidase with dispersal of cumulus still continue, and the possibility that hyaluronidase facilitates the passage of the fertilizing spermatozoon through the intercellular matrices cannot be excluded altogether. For the moment, however, the process whereby the ovum is freed from the cumulus still remains obscure, and recent research indicates that the mechanical action of the oviduct or some other tubal factor may be more important in this respect than the activity of hyaluronidase. Moreover, in rodents, the entry of the spermatozoon into the egg has been observed at a stage where the egg is still surrounded by the cumulus.

"Sperm-egg Interacting Substances and Metabolic Changes Associated with Fertilization" were discussed by Lord Rothschild (Department of Zoology, Cambridge). Present knowledge concerning this subject still remains confined largely to lower animals. Gamones or sperm-egg interacting substances play a part in activation, inactivation and agglutination of spermatozoa, and are also concerned with the precipitation or dissolution of the egg jelly and the liquefaction of the egg cortex. In sea-urchins a host of striking changes take place at fertilization, including acid production, a fall in respiratory quotient, reduction in glycogen content, liberation of ammonia and calcium, and increase in uptake of inorganic phosphate, as well as characteristic changes in the activity of certain enzymes. Contrary to earlier views, the cytochrome system is now known to function in both fertilized and unfertilized eggs, and the photoreversible inhibition of respiration by carbon monoxide has been clearly demonstrated in both fertilized and unfertilized eggs, as well as in sea-urchin spermatozoa.

So far as the animal kingdom is concerned, the evidence for the occurrence of chemotaxis of spermatozoa towards eggs still requires confirmation. Studies on plants, on the other hand, have provided several clear instances of chemotaxis. The recent developments in "Biochemistry of Sexual Reproduction in Plants" were described by Dr. Lilian Hawker (Department of Botany, Bristol), who gave many interesting examples derived from studies on both lower and higher plants. The spore-promoting effects of factors $Z_{1}$ and $Z_{2}$ (the former replaceable by certain purines) and the stimulating influence of thiamin and biotin on sexual reproduction and mycelial growth are among the phenomena which were extensively studied in fungi. The action of the sexcontrolling hormones in algx, the chemotactic phenomena in ferns and mosses, and the flowerpromoting activity of 'florigen' are among the multitude of other problems in plant physiology which are now open to biochemical investigations.

T. MANN

\section{DEPARTMENT OF THE GOVERNMENT CHEMIST}

\section{ANNUAL REPORT FOR 1949-50}

$A$

REPORT on the work of the Department of the Government Chemist, covering the year ended March 31, 1950*, has been issued for the first time since 1939, and a list of publications by members of the Department, 1939-50, is appended. The total number of samples examined in the Department was 414,172 , as against 363,753 in $1948-49$, and was greater than in any year since 1939-40 or 1938-39, when 560,354 and 555,045 samples, respectively, were examined. Much of the work, however, was not related to samples: even the Revenue branches, which deal with a very large volume of routine samples, were involved in protracted technical discussions in connexion with the proposed adoption by Western Union countries of a common tariff nomenclature, and collaborative work with the Customs and Excise Department has been carried out to ascertain how the United Kingdom tariff system would fit in with such a nomenclature. Work on the determination of moisture in tobacco and on the design of polarimeters and saccharimeters is also being prosecuted; and the Department is called upon to give technical advice on a wide range of questions dealing with the administration of the hydrocarbon oil duty.

In 1946 the personnel of the Department was regraded on the lines recommended in the White Paper on the Scientific Civil Service and the work re-organized. Besides the two Revenue Branches, there is the Food, Drugs and Agricultural Branch, consisting of six divisions. Besides his statutory position under the Food and Drugs Act, 1938, and the Fertilizer and Feeding Stuffs Act, 1926, the Government Chemist has now a statutory obligation under the National Health Service Act, 1946, as referee in disputes over analyses of drugs. An important function of this Branch is also to provide a service for the control of the quality of many articles with which government departments are concerned as consumers or suppliers. Work continued on the microbiological assay of riboflavine; and, in collaboration with the Ministry of Health, an investigation into some aspects of the physiology of athletes was conducted at the time of the Olympic Games in 1948, which gave daily calorie intakes much lower than those obtained at the Berlin Olympiad, varying from more than 4,600 Calories for one British to 2,100 Calories for one Mexican competitor. Of reference samples submitted under the Food and Drugs Act, determination of a small quantity of glycerol in a medicine containing sugars was most troublesome, and methods based on solubility had to be used.

The Industrial and Mineral Branch is responsible for work arising out of the quality control of supplies of materials purchased to specification for use in the public service, from the statutory obligations of government departments involving chemical control (for example, the use of leadless or low.solubility glazes in pottery, or petroleum solvents under the India Rubber Regulations) or from the Department's function as an official chemical consultant. Besides determinations of fluorine in fossil bones for the Geological Department of the British Museum

* Report upon the Work of the Government Chemist for the Year ending 31 st March, 1950. Pp. 36. (London: H.M. Stationery Office, 195il.) 18 . net 